\title{
As ações educativas ambientais das Organizações Não Governamentais ambientalistas no estado de São Paulo, Brasil
}

\author{
The environmental and educational actions developed by the Environmental Non- \\ Governmental Organizations in São Paulo state, Brazil
}

\section{Las acciones educativas ambientales de las Organizaciones No Gubernamentales ambientales en el estado de São Paulo, Brasil}

\author{
André Santachiara Fossaluza ${ }^{1}$ \\ Marília Freitas de Campos Tozoni Reis ${ }^{2}$ \\ Maria Cecília Evangelista ${ }^{3}$ \\ Carlos Roberto Padovani ${ }^{4}$
}

\begin{abstract}
Resumo
As ONGs ambientalistas têm desempenhado relevante papel nas ações em educação ambiental (EA), mundialmente. Devido à escassez de pesquisas abrangentes a identificação e atuação delas, este artigo apresenta um mapeamento das ONGs ambientalistas, no estado de São Paulo, que atuam com EA, além de analisar a qualidade de algumas dessas ações. A consulta em quatro bases de dados encontrou 276 ONGs ambientalistas, sendo que $63 \%$ delas atuam com EA. Realizamos, também, entrevistas semiestruturadas com membros das ONGs, o que nos permitiu analisar as ações em EA a partir dos objetivos apresentados pelas próprias organizações, classificando-as quanto a sua tendência político-pedagógica predominante. Os resultados evidenciam que as ONGs ambientalistas estão distribuídas em uma parte significativa do território paulista e têm atuação relevante, ainda que as ações sejam predominantemente de cunho conservacionista e, sob referenciais teóricos críticos em EA, tenham uma qualidade limitada e questionável.
\end{abstract}

Palavras-chave: Educação ambiental. ONG ambientalista. Sustentabilidade.

\begin{abstract}
The Environmental NGOs (ENGOs) have performed a relevant role to environmental education actions worldwide. Due to the lack of wide works regarding its identification and performance, this article presents a mapping of the ENGOs in São Paulo state, Brazil, that work with environmental education and analyses the quality of some of these actions. We consulted four databases, where we found 276 ENGOs, of which $63 \%$ act with environmental education. We also conducted semi-structured interviews with members of the ENGOs, which allowed us to analyze the quality of these actions considering the objectives provided by the organizations, categorizing them according to their main political and pedagogical trend. The results highlight that the ENGOs are widespread in a significant area of São Paulo's territory and have a relevant performance, even though most of their educational actions have a conservationist nature and tend to have low and questionable quality under critical theoretical frameworks of environmental education.
\end{abstract}

\footnotetext{
${ }^{1}$ Doutor em Educação para a Ciência, Universidade Estadual Paulista (UNESP), Faculdade de Ciências, campus de Bauru, SP, Brasil; Agente de Educação Ambiental, Serviço Social do Comércio (SESC-SP), unidade Jundiaí, SP, Brasil. E-mail: fossaluza.andre@ gmail.com

${ }^{2}$ Livre-Docente em Educação, Professora voluntária, Universidade Estadual Paulista (UNESP), Instituto de Biociências, Departamento de Educação, campus de Botucatu, SP, Brasil. E-mail: mariliatozoni@uol.com.br ${ }^{3}$ Mestre em Biometria, Estatística, Hospital do Câncer, Barretos, SP, Brasil. E-mail: emariacecilia0@gmail.com ${ }^{4}$ Livre-Docente em Estatística Experimental, Professor Titular, Universidade Estadual Paulista (UNESP), Instituto de Biociências, Departamento de Bioestatística, campus de Botucatu, SP, Brasil. E-mail: cr.padovani@unesp.br
} 
Keywords: Environmental education. ENGO. Sustainability.

\section{Resumen}

Las ONGs ambientalistas han sido muy importantes para la educación ambiental en todo el mundo. Debido a la escasez de investigaciones extensas acerca de su identificación y acción, este artículo presenta un mapeo de las ONGs ambientalistas en el estado de São Paulo, Brasil, que trabajan con educación ambiental, además de analizar su calidad bajo un marco crítico. Al consultar cuatro bases de datos, encontramos 276 ONGs ambientalistas, siendo que $63 \%$ de ellas actúan con educación ambiental. Hicimos entrevistas con miembros de las ONG, lo que nos permitió analizar la calidad de las acciones desde los objetivos presentados por las ONGs, clasificándolas cuanto a su tendencia política y pedagógica predominante. Los resultados evidencian que las ONGs ambientalistas se distribuyen en un área significativa del territorio de São Paulo y tienen actuación relevante, aunque la mayor parte de las acciones educativas tengan un perfil conservacionista y calidad limitad y cuestionable cuando las analizamos según referencias teóricas críticas en educación ambiental.

Palabras-clave: Educación ambiental. ONG ambientalista. Sostenibilidad.

\section{Introdução}

Este estudo é consequência de questionamentos após anos atuando em Organizações Não Governamentais (ONGs) nas áreas ambiental e educacional. Apesar da visibilidade, ainda é desafiador encontrar o caminho para informações sobre como essas organizações são compostas, como atuam, quais são seus objetivos e sua importância na sociedade.

Entendemos o surgimento dessas ONGs como uma resposta às problemáticas ambientais que se agravaram em consequência das transformações que a vida moderna trouxe às sociedades. $\mathrm{O}$ modo capitalista de produção, unido à ciência, promoveu o desenvolvimento econômico e científico num ritmo acelerado, ainda que de forma desigual, ao redor do mundo e em diferentes momentos históricos. A humanidade entrou nessa etapa com novas estruturações de poder e com novos problemas políticos e sociais, entre eles, o ambiental (TOZONI-REIS, 2008).

A partir da década de 1960, especialmente, essas preocupações se avolumaram, fomentando o desenvolvimento da educação ambiental (EA). No Brasil, ela surgiu institucionalmente em 1973, após as recomendações políticas elaboradas na Conferência das Nações Unidas sobre o Meio Ambiente Humano, em Estocolmo, no ano de 1972 (CARVALHO, 2008).

Nas décadas seguintes, as políticas públicas em EA se desenvolveram. Dentre elas, destacamos o Fórum Global, evento que aconteceu simultaneamente à Conferência das Nações Unidas sobre o Meio Ambiente Humano de 1992 (ECO 92), como um marco importante da atuação da sociedade civil para a EA, por meio da promulgação do Tratado de EA para Sociedades Sustentáveis e Responsabilidade Global (BRASIL, 2018). Para sua elaboração, a participação de 1.500 ONGs foi de grande relevância e evidenciou o fortalecimento dessas entidades.

As ONGs são comumente definidas como organizações que não visam à obtenção de lucro nas suas atividades, diferindo radicalmente de empresas. Além disso, são conhecidas por fazerem um contraponto às ações do governo e do mercado, por realçarem a importância de ações sem fins lucrativos e por projetarem uma integração entre as ações públicas e privadas na sociedade (ALBUQUERQUE, 2006).

Elas também são classificadas como entidades que compõem o terceiro setor e que atendem, simultaneamente, a cinco categorias: estarem organizadas formalmente, serem privadas, administrarem suas próprias atividades, não distribuírem lucros a seus membros e terem alto grau de participação cidadã (ONU, 2003). Dessa forma, extrapola-se a tendência à 
simplificação da caracterização do chamado terceiro setor apenas como entidades sem fins lucrativos.

Pinto (2006) discute como a participação da sociedade civil passou a se expandir, principalmente, após o término do período ditatorial civil-militar no Brasil. As ONGs, como parte das Organizações da Sociedade Civil, são definidas como instituições que "não são governamentais, não são lucrativas, não fazem parte de estruturas maiores, não são representativas, não financiam" (FERNANDES, 1994, p.25) e, ainda, que se apresentam como não partidárias (PINTO, 2006).

Além disso, a autora estabelece as diferenças entre essas e os movimentos sociais. Podemos dizer que algumas ONGs são resultantes da profissionalização da militância de movimentos sociais, ainda que essa não seja sua única origem. Há organizações que surgem da reunião de "grupos de profissionais envolvidos com causas específicas, de ex-militantes políticos" (PINTO, 2006, p.657) e grupos de amigos/as com causas comuns. Apesar de compartilharem demandas e ações com os movimentos sociais, as ONGs possuem funcionamentos distintos:

\footnotetext{
Uma ONG só existe por intermédio de projetos que a sustentem, ela é proativa, tem metas a cumprir, programas preestabelecidos e financiados. Os movimentos sociais são menos estruturados, não prestam contas, nem têm um grupo de profissionais para sustentar. As ONGs formalizam-se, possuem diretorias, conselhos e corpo de funcionários. Isto pode levar, pelo menos em tese, a um processo de autorreferência muito grande, no qual sua reprodução como organização tenha quase tanta centralidade como a causa que defende (PINTO, 2006, p.656).
}

Após compreender a natureza das ONGs, destacamos aquelas que atuam na área ambiental. Almeida-Júnior e Gomes (2012, p. 168-169) discutem que a expansão da atuação das ONGs ambientalistas foi fomentada, entre outros motivos, pela "falta de credibilidade das corporações nas questões ambientais". Ainda, os autores defendem que esse panorama promoveu o surgimento de "ONGs que executam projetos socioambientais com recursos das empresas, instituições que publicam índices socioambientais e outros agentes que testemunham sobre as ações, os produtos, os projetos e as tecnologias de produção empregadas pelas corporações".

Essa atuação foi analisada em várias publicações, sendo reconhecido que muitas delas desenvolvem ações educativas. Um mapeamento de 2013, por exemplo, encontrou 327 ONGs ambientalistas atuando no Brasil, sendo que 93,9\% delas realizavam, à época do levantamento, trabalhos em EA (ANÁLISE EDITORIAL, 2013).

Rodrigues e Loureiro (2012) questionam a atuação legitimada dessas organizações em situações em que deveria haver a presença do Estado e a sua promoção como entidades que surgem para resolver problemas sociais de forma ética e compromissada, não considerando suas relações com os financiadores, como bancos e empresas que atuam para a manutenção do atual sistema produtivo. Diegues (2008, p. 160) aponta, ainda, que "apesar do aumento do poder das ONGs para influenciar as políticas ambientais nacionais e internacionais, a cooptação crescente de muitas delas pela esfera governamental tem enfraquecido sua ação”.

Apesar desse rico debate, são raros os trabalhos que analisam, de forma aprofundada, as ações das ONGs ambientalistas. Encontramos estudos que analisam ações educativas de uma ou duas entidades ambientalistas para, então, discutir o papel das ONGs na EA (SILVA, 2012; TEIXEIRA; TALAMONI; TOZONI-REIS, 2013). Outros trabalhos apresentam critérios para avaliação de projetos e ações em EA (CARLETON-HUG; HUG, 2010; EAMES; COWIE; 
BOLSTAD, 2008; GUANABARA; GAMA; EIGENHEER, 2009; SAITO, 2011); eles, porém, não foram utilizados em análises posteriores mais amplas ou ficaram restritos a certa localidade.

Percebemos, assim, a necessidade de estudos que aprofundem as análises sobre a atuação das ONGs ambientalistas em EA partindo de uma fonte de dados mais ampla e aprofundada, que possa sustentar as discussões e compreender esse complexo setor da sociedade.

Para tal aprofundamento, faz-se necessário discutir o que entendemos por EA e quais são nossos referenciais teóricos para a pesquisa.

A EA se desenvolveu, com mais intensidade, a partir da metade do século XX, apesar de estar presente em diversos momentos da história. Os intensos reflexos sociais e ambientais causados pelo modo capitalista de produção começaram a ser analisados, mais sistematicamente, a partir do fim da $2^{\text {a }}$ Guerra Mundial, como no livro "Primavera Silenciosa", de Rachel Carson, publicado em 1962.

Nesse contexto, surgem ações de caráter prioritariamente ativista em defesa do ambiente. Tais práticas desembocam em ações de EA de caráter conservacionista, no sentido de "uma prática educativa que tinha como horizonte o despertar de uma nova sensibilidade humana para com a natureza, desenvolvendo-se a lógica do "conhecer para amar, amar para preservar", orientada pela conscientização "ecológica e tendo por base a ciência ecológica" (LAYRARGUES; LIMA, 2014, p.27). Os autores defendem que esse caráter da EA se desenvolve após a percepção dos efeitos imediatos da degradação ambiental, além de uma compreensão simplista das relações entre a sociedade e a natureza.

Com o avanço das pesquisas em EA, novas interpretações da realidade e da relação entre humanidade e natureza começam a ser discutidas. Sauvé (2005) traz que, ainda que as ações em EA compartilhem a preocupação com o ambiente e o reconhecimento do papel da educação na melhoria das relações entre humanos e ambiente, é possível identificar, pelo menos, quinze correntes em EA, algumas com longa tradição (e.g. correntes naturalista, sistêmica, humanista etc.) e outras mais recentes (e.g. holística, crítica, feminista, da sustentabilidade etc.).

Entre diversos/as autores/as que sintetizaram diferentes correntes em EA, destacamos a análise de Layrargues e Lima (2014), que apresentam três macrotendências políticopedagógicas para a EA: conservacionista (apresentada acima), pragmática e crítica.

As ações de caráter pragmático têm como foco a mudança de comportamentos para um melhor uso dos recursos naturais, uma "expressão do ambientalismo de resultados, do pragmatismo contemporâneo e do ecologismo de mercado que decorrem da hegemonia neoliberal" (LAYRARGUES; LIMA, 2014, p. 31). Segundo os autores, essa perspectiva se tornou predominante a partir de 1980, com a máxima do pensar globalmente, agir localmente: a soma dos esforços individuais promoveria uma mudança no todo. Por isso, ela se alinha ao discurso Neoliberal ao não questionar as desigualdades sociais e as formas de opressão que levam a profundas problemáticas ambientais e sociais.

Já as ações de caráter crítico, com as quais desenvolvemos as análises deste trabalho, entendem que não é possível mudar as relações entre sociedade e natureza sem transformar o próprio modo de produção que domina a sociedade humana. Superando as concepções conservadoras apresentadas acima, mas não desmerecendo sua legitimidade e importância, entende-se que é necessário "contextualizar e politizar o debate ambiental, problematizar as contradições dos modelos de desenvolvimento e de sociedade" (LAYRARGUES; LIMA, 2014, p. 33). Nesse sentido, Tozoni-Reis (2011, p. 293), expõe que:

Acreditamos, portanto, que o processo educativo ambiental não se resume em ensinar as características físicas, químicas e biológicas dos sistemas ecológicos e/ou as suas dinâmicas (...). Trata-se, pois, de problematizar, no processo educativo, o papel do ser 
humano na biosfera e de possibilitar a compreensão das complexas relações estabelecidas entre a sociedade e a natureza, bem como dos processos históricos que condicionam a organização das relações sociais nas sociedades.

Defendemos a EA que tem como base concepções críticas de educação. Da mesma forma que Paulo Freire (2020), entendemos a educação como uma experiência especificamente humana, como forma de intervenção no mundo. Ao se configurar como uma atividade não neutra e praticada por seres humanos constituídos a partir de múltiplas ordens de materialidade, com condicionantes biológicos, culturais, sociais, políticos e históricos, a educação pode capacitá-los a investigar, desvendar e compreender as contradições da sociedade na perspectiva de sua transformação.

Com essa premissa, este estudo analisa a qualidade das ações em EA desenvolvidas por ONGs, tendo como base referenciais teóricos críticos. Tais análises surgem do nosso histórico de atuação junto a diversas entidades - atuação que nos mostrava uma atuação prática, real, que contradizia as bases teóricas anunciadas como críticas. Ademais, notamos ser necessário partir de uma ampla fonte de dados acerca das ONGs ambientalistas, que possa basear as discussões sobre esse complexo setor.

Nesse sentido, este artigo apresenta um mapeamento das ONGs ambientalistas do estado de São Paulo (SP) e identifica quais delas desenvolvem ações em EA, de maneira a discutir sua abrangência de atuação e a analisar a qualidade dessas ações educativas, levando em consideração os objetivos apresentados pelas próprias ONGs ambientalistas e tendo como categoria de análise sua macrotendência político-pedagógica predominante ${ }^{5}$.

\section{Metodologia}

A metodologia de coleta e análise de dados foi dividida em duas seções. A primeira delas apresenta o universo de pesquisa e o caminho para o mapeamento das ONGs ambientalistas no estado. A segunda seção discute as bases para coleta e análise de dados qualitativos que foram utilizados para as discussões sobre a qualidade das ações em EA.

O universo de pesquisa é o estado de São Paulo, que possui população de 41.262.199 pessoas, distribuída em 645 municípios (IBGE, 2010). Em 2014, estimava-se que essa população fosse de 44.035 .304 pessoas.

Num primeiro momento, buscamos definir quais plataformas seriam utilizadas para o trabalho de mapeamento. Buscamos informações junto à Associação Brasileira de Organizações Não Governamentais (ABONG): apesar da riqueza de informações sobre essas organizações a nível nacional, não encontramos uma listagem específica sobre ONGs ambientalistas. Situação similar ocorreu ao procurarmos informações na Rede Paulista de EA (REPEA), a qual, apesar de possuir muitos dados, não os apresenta de forma sistematizada.

Encontramos, porém, quatro bancos de dados com informações bem-organizadas e disponíveis. Dois deles são públicos; outros dois, privados. Notamos que as informações apresentadas por cada um deles não são similares, ou seja, organizações que aparecem em um deles não necessariamente estão presentes noutros; além disso, muitos dos dados estão desatualizados.

\footnotetext{
${ }^{5} \mathrm{O}$ presente artigo é recorte de uma pesquisa de mestrado, a qual analisou outros critérios além dos objetivos das ações em educação ambiental apresentados pelas ONGs. O trabalho completo está disponível no endereço https://repositorio.unesp.br/handle/11449/124012.
} 
Assim, trabalhamos com o intuito de combinar os dados e criar uma única lista de ONGs ambientalistas atuantes no estado (Quadro 1). As quatro bases de dados encontradas foram ${ }^{6}$ :

1) Cadastro Nacional de Entidades Ambientalistas (CNEA): sítio eletrônico, público, Ministério do Meio Ambiente (BRASIL, 2013).

2) Cadastro de Entidades Ambientalistas de São Paulo (CadEA): sítio eletrônico, público, Coordenadoria de EA do Estado de São Paulo (SÃO PAULO, 2013).

3) Made in Forest: sítio eletrônico, privado (MADE IN FOREST, 2014) ${ }^{7}$.

4) Análise Gestão Ambiental: publicação impressa, privada (ANÁLISE EDITORIAL, 2013).

\begin{tabular}{|c|c|}
\hline Base de dados & Quantidade de ONGs listadas \\
\hline CNEA & 120 \\
\hline CadEA & 46 \\
\hline Made in Forest & 62 \\
\hline Análise Gestão Ambiental & 152 \\
\hline Total & $\mathbf{3 8 0}$ \\
\hline
\end{tabular}

Quadro 1 - Quantidade de ONGs ambientalistas encontradas nas diferentes bases de dados consultadas Fonte: Fossaluza (2015)

Para descobrir se as organizações continuam atuantes e quais delas desenvolvem ações em EA. Para isso, buscamos contatar todas as ONGs ambientalistas listadas.

Os contatos foram realizados por telefone ou e-mail, de maio a junho de 2014. Quando as chamadas telefônicas não foram atendidas, enviamos um e-mail ou preenchemos formulários disponibilizados nos sites dessas entidades. Quando nenhuma dessas alternativas foi bemsucedida, fizemos uma pesquisa em mecanismos de busca on-line. Somente após o esgotamento de todas essas tentativas, consideramos que a ONG não atua mais ou, ainda, não oferece nenhuma condição para contato.

Os dados das ONGs e sua atuação foram organizados em quatro agrupamentos:

1) ONGs ambientalistas com atuação em EA: organizações que puderam ser contatadas e/ou disponibilizam informações sobre sua atuação virtualmente e que trabalham com EA.

2) ONGs ambientalistas sem atuação em EA: organizações que puderam ser contatadas e/ou disponibilizam informações sobre sua atuação virtualmente e que não trabalham com EA.

3) ONGs ambientalistas com atuação em EA indefinida: organizações que não puderam ser contatadas e/ou não disponibilizam informações sobre sua atuação virtualmente.

4) ONGs ambientalistas que não puderam ser contatadas (sem contatos válidos): organizações que não puderam ser contatadas ( $e$-mails e telefones inválidos) e que não possuem site em funcionamento.

Após o trabalho de mapeamento, passamos à fase de coleta de dados de ordem qualitativa. Aqui, determinamos uma amostra das ONGs que seriam entrevistadas, com um

\footnotetext{
${ }^{6}$ É importante ressaltar que as bases de dados utilizadas estavam disponíveis durante o período de coleta de dados. Enquanto as plataformas públicas continuam a ser atualizadas, as bases privadas não apresentam atualizações recentes.

${ }^{7}$ Atualmente (2021), o endereço eletrônico está desativado.
} 
processo de seleção que promoveu validade externa ao estudo, ou seja, que tem representatividade frente ao universo de pesquisa.

Essa amostra foi determinada buscando garantir um bom Nível de Confiança (95\%), baixo erro de estimação $(10 \%)$ e alta aderência $(85 \%)$, a partir da fórmula ${ }^{8}$ :

$$
\mathrm{n}=\frac{\mathrm{N} \cdot \mathrm{p} \cdot \mathrm{q} \cdot\left(\mathrm{Z}_{\alpha / 2}\right)^{2}}{\mathrm{p} \cdot \mathrm{q} \cdot\left(\mathrm{Z}_{\alpha / 2}\right)^{2}+(\mathrm{N}-1) \cdot \mathrm{E}^{2}}
$$

O processo de seleção das ONGs a serem entrevistadas foi randômico. Quando não conseguíamos entrar em contato com a ONG sorteada (via telefone ou correio eletrônico) ou conseguíamos entrar em contato, mas a realização da entrevista não era possível, sorteávamos uma nova ONG.

$\mathrm{Na}$ análise, levamos em consideração as condições históricas determinantes da vida dos sujeitos na sociedade capitalista, isto é, levando em conta a formação econômica (TOZONIREIS, 2007) e não se excluindo outros determinantes que influenciam no processo de ordem cultural, biológica, política, religiosa e outras. Além disso, ao entendermos a EA como um estudo das relações entre seres humanos e desses com a natureza, é necessário compreendê-la pela superação da lógica formal cartesiana (MINAYO et al., 1994), exigindo, nesse contexto, uma abordagem qualitativa. Isso significa dizer que este estudo tem como referência a pesquisa qualitativa, mas não exclui os dados quantitativos que foram interpretados sob a luz dos estudos da abordagem escolhida.

Para realizar a interpretação dos dados, optamos pela Análise de Conteúdo proposta por Bardin (2011, p. 37), a qual pode ser definida como um "conjunto de técnicas de análise das comunicações". Segundo a autora, o campo de aplicação desse método é muito vasto e se encaixa em "qualquer comunicação, isto é, qualquer veículo de significados de um emissor para um receptor, controlado ou não por este, deveria poder ser escrito, decifrado pelas técnicas de análise de conteúdo" (BARDIN, 2011, p.38).

Ela apresenta, também, que a Análise de Conteúdo possui duas funções: a heurística e a de administração da prova, as quais podem, ou não, se dissociar na prática Enquanto a primeira se refere à exploração e à descoberta de novas informações, a segunda busca formular hipóteses ou questões iniciais que serão colocadas à prova posteriormente: "É a Análise de Conteúdo 'para servir de prova"” (BARDIN, 2011, p.36).

Consideramos que ambas as funções são aplicáveis a este estudo, cada qual relacionada a um objetivo proposto: a função heurística nos auxiliará no mapeamento das ONGs que desenvolvem ações em EA, enquanto a função de administração da prova contribuirá na análise dessas ações.

Como também apresentado por Bardin (2011), a Análise de Conteúdo foi organizada em (1) Pré-Análise; (2) Exploração do Material; e (3) Tratamento dos resultados, inferência e interpretação.

A Pré-Análise consiste na fase de organização do trabalho de pesquisa e tem como objetivo tornar operacionais e sistematizar as ideias iniciais. A autora sugere que essa organização não é sinônimo de rigidez e pode, portanto, ser flexível; deve-se, porém, buscar a

\footnotetext{
${ }^{8}$ Onde: $\mathrm{N}=$ Número de indivíduos do universo de pesquisa. $\mathrm{n}=$ Número de indivíduos na amostra, $\mathrm{Z} \alpha / 2=\mathrm{Valor}$ crítico que corresponde ao grau de confiança desejado - no caso, 1,96. p = Proporção populacional de indivíduos que pertence a categoria que estamos interessados em estudar. q = Proporção populacional de indivíduos que não pertencem à categoria que estamos interessados em estudar $(\mathrm{q}=1-\mathrm{p})$. $\mathrm{E}=$ Margem de erro ou erro máximo de estimativa. Identifica a diferença máxima entre a proporção amostral e a verdadeira proporção populacional (p).
} 
maior precisão possível. Essa primeira fase possui três missões: "a escolha dos documentos a serem submetidos à análise, a formulação das hipóteses e dos objetivos e a elaboração de indicadores que fundamentem a interpretação final" (BARDIN, 2011, p.124).

A Exploração do Material se refere à "aplicação sistemática das decisões tomadas" (BARDIN, 2011, p.131). É nesse momento que, tanto as informações obtidas através de documentos (função heurística) quanto por meio das entrevistas (função de administração de provas), são organizadas de acordo com os indicadores apresentados anteriormente.

A última fase da análise de conteúdo, o Tratamento dos resultados, a inferência e interpretação, consiste em tornar os dados coletados válidos e significativos. Bardin (2011, p.131) expõe que "operações estatísticas simples (percentagens), ou mais complexas (análise fatorial), permitem estabelecer quadros de resultados, diagramas, figuras e modelos, os quais condensam e põem em relevo as informações fornecidas pela análise". A partir dessa sistematização, é possível a proposição de inferências e interpretações para atingir os objetivos propostos, de acordo com o referencial teórico adotado.

Os dados de ordem qualitativa foram coletados a partir de entrevistas realizadas com membros representantes das ONGs, além de informações complementares disponibilizadas nos sites das organizações. Todas as entrevistas foram integralmente gravadas e parcialmente transcritas. Todas as pessoas participantes foram apresentadas ao Termo de Consentimento Livre e Esclarecido e, após sua leitura, concordaram em participar da pesquisa, optando livremente pela divulgação ou não do (1) conteúdo da entrevista, (2) fotografias da entrevista, (3) nome da ONG, (4) endereço da ONG e (5) contatos da ONG (telefone, sítio eletrônico e $e$ mail) (FOSSALUZA, 2015).

A entrevista, como definida por Haguette (2010, p. 81), é um "processo de interação social entre duas pessoas na qual uma delas, o entrevistador, tem por objetivo a obtenção de informações por parte do outro, o entrevistado". Optamos pela entrevista semiestruturada, definida por Boni e Quaresma (2005, p. 8):

\footnotetext{
As entrevistas semiestruturadas combinam perguntas abertas e fechadas, onde o informante tem a possibilidade de discorrer sobre o tema proposto. $\mathrm{O}$ pesquisador deve seguir um conjunto de questões previamente definidas, mas ele o faz em um contexto muito semelhante ao de uma conversa informal. O entrevistador deve ficar atento para dirigir, no momento que achar oportuno, a discussão para o assunto que o interessa fazendo perguntas adicionais para elucidar questões que não ficaram claras ou ajudar a recompor o contexto da entrevista, caso o informante tenha "fugido" ao tema ou tenha dificuldades com ele.
}

Para a formulação das hipóteses e dos objetivos da análise de conteúdo, além da elaboração de indicadores que fundamentam a interpretação final, baseamo-nos em estudos que propuseram ferramentas para avaliar projetos de EA em diferentes contextos, adaptados ao referencial teórico norteador deste trabalho.

Eames, Cowie e Bolstad (2008), ao avaliarem as práticas em EA desenvolvidas nas escolas neozelandesas, dividiram as ações realizadas em educação para o ambiente, educação no ambiente e educação sobre o ambiente. A análise quantitativa e qualitativa forneceu um amplo e representativo panorama da EA escolar neozelandesa.

Já Guanabara, Gama e Eigenheer (2009) propõem uma matriz para avaliar projetos de EA a partir de ações realizadas no estado do Rio de Janeiro, numa contribuição que avaliamos como mais adequada para a determinação dos indicadores. Apesar do foco dessas ações serem relacionadas à gestão de resíduos sólidos, a matriz proposta permite analisar, primeiramente de forma qualitativa, se tais ações são condizentes com a legislação aplicável ao caso. Num segundo momento, são atribuídos valores às respostas dadas a cada item, fato que permite uma 
análise quantitativa dos projetos. Nesse estudo, foram apresentados treze critérios para avaliar se os projetos estavam em consonância com as legislações federal e estadual relativas ao tema.

Tendo em mente que trazemos como objetivo analisar a qualidade das ações em EA realizadas por ONGs ambientalistas, optamos por partir dos objetivos das ações em EA apresentados pelas próprias organizações: entendemos que a expressão dos objetivos permite analisar qual macrotendência político-pedagógica de EA norteia as ações e serve como indicador da sua qualidade. Atividades baseadas em concepções conservacionistas ou pragmáticas, por exemplo, sob a perspectiva crítica que orienta este estudo, teriam pouco impacto na formação de sujeitos críticos que possam atuar como agentes políticos na transformação da realidade social e ambiental. Além disso, intersecções entre concepções de EA contraditórias podem contribuir para enfraquecer - ou não - as ações formativas.

Para obtermos os dados para a nossa análise, abordamos os seguintes temas nas entrevistas: (1) ações em EA desenvolvidas pela ONG e (2) seus objetivos.

\section{Resultados e discussão}

Tendo como base nosso referencial teórico e metodológico, formulamos a hipótese inicial de que os objetivos das ações em EA desenvolvidos por ONGs ambientalistas tendem a se aproximar das macrotendências político-pedagógicas conservacionista e pragmática de EA, o que conferiria baixa qualidade crítica às mesmas e levaria a impactos menos significativos nas relações entre a sociedade e o ambiente.

Os resultados da pesquisa são organizados em duas seções: a primeira delas traz os dados relativos ao mapeamento das ONGs ambientalistas e discute a disposição dessas organizações no território; a segunda apresenta e discute os dados relativos à qualidade das ações em EA, fomentando o diálogo com as informações obtidas no mapeamento.

\subsection{Mapeamento e distribuição territorial das ONGs ambientalistas no estado de São Paulo}

A partir da consulta às bases de dados citadas e com o cruzamento desses dados para verificar repetições e diferenças entre elas, encontramos um total de 276 ONG ambientalistas no estado de São Paulo.

As 276 ONGs ambientalistas encontradas estão distribuídas em 104 municípios do estado de São Paulo, valor que corresponde a 16,12\% do total do número de cidades, mas que abrigam $68,15 \%$ da população do estado (aproximadamente 28 milhões de pessoas) ${ }^{9}$. Isso significa que, embora as ONGs estejam presentes numa pequena porcentagem dos municípios paulistas, mais da metade da população estadual convive, direta ou indiretamente, com sua atuação nas cidades onde residem.

Ao analisarmos a distribuição dessas ONGs ambientalistas no território, pudemos notar uma maior concentração em cidades próximas à capital e no litoral. Neste trabalho, entretanto, não temos dados suficientes para discutir com profundidade os motivos desse panorama. É possível afirmar que nessas regiões existem grandes extensões de Unidades de Conservação (UCs), como o Parque Estadual da Serra do Mar, mas não verificamos se existe alguma relação entre a quantidade de ONGs ambientalistas e a presença de UCs.

\footnotetext{
${ }^{9}$ Atualmente, existem 645 municípios no estado de São Paulo, com população total de 44.639 .899 habitantes em 2018. Fonte: http://www.bibliotecavirtual.sp.gov.br/temas/sao-paulo/sao-paulo-populacao-dos-municipiospaulistas.php. Acesso em: 22 out. 2020.
} 
Pudemos, entretanto, analisar se existe alguma relação aparente entre a quantidade de ONGs ambientalistas numa localidade e a sua população. Para tal, calculamos a densidade de ONGs ambientalistas nas cidades onde elas estão presentes (razão entre número de habitantes do município e quantidade de ONGs) e criamos uma escala para classificar municípios com maior ou menor densidade de ONGs.

Essa escala foi composta de cinco classificações (Figura 1):

(1) densidade muito alta de ONGs (até 10.000 habitantes por ONG);

(2) densidade alta (de 10.001 a 50.000 habitantes por ONG);

(3) densidade média (50.001 a 100.000 habitantes por ONG);

(4) densidade baixa (100.001 a 200.000 habitantes por ONG);

(5) densidade muito baixa (mais de 200.001 habitantes por ONG).

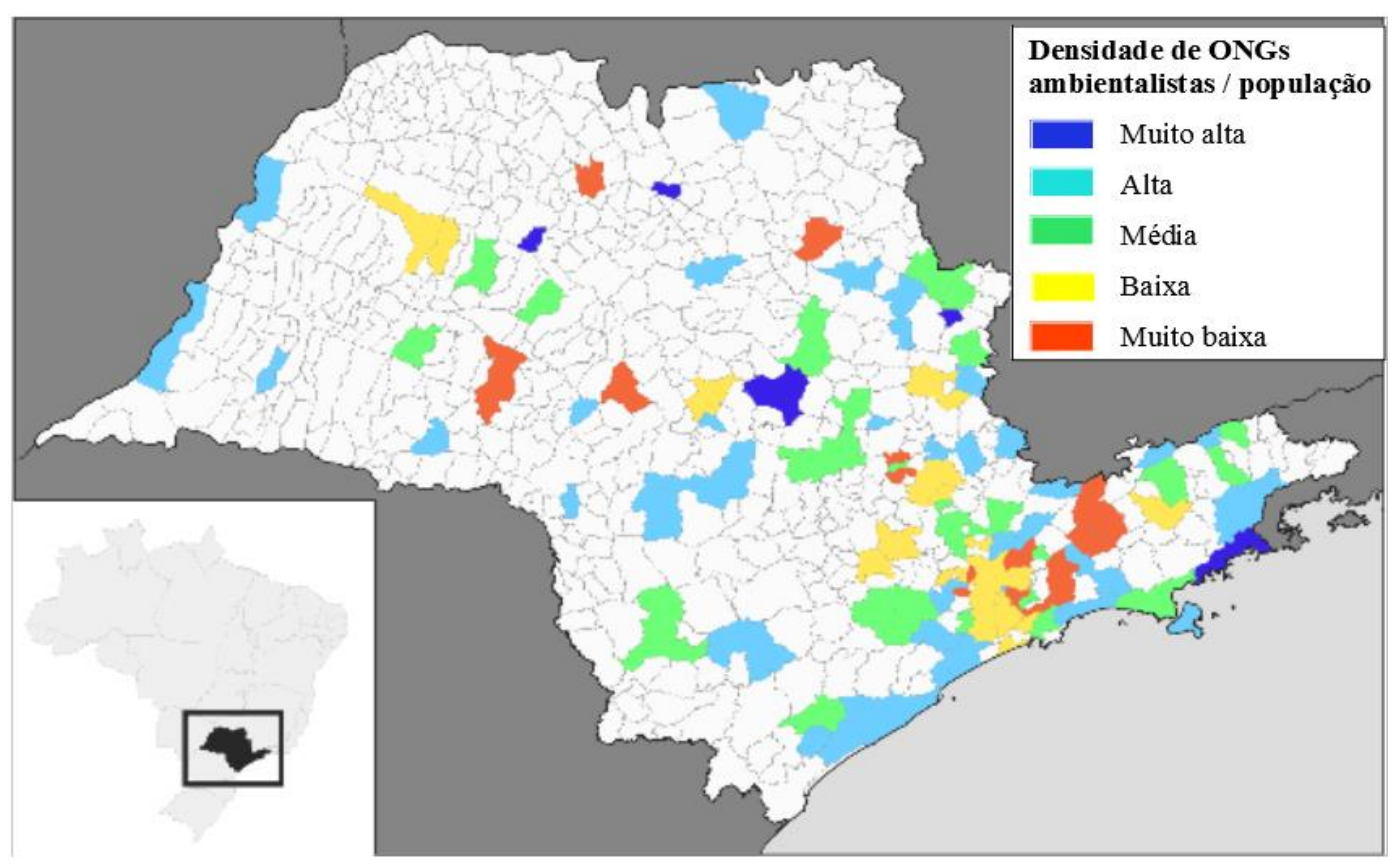

Figura 1 - Disposição territorial e densidade de ONGs ambientalistas no estado de São Paulo Fonte: Fossaluza (2015)

No Quadro 2 apresentamos os municípios do estado de São Paulo onde encontramos ONGs ambientalistas, sendo que 43 municípios possuem densidade muito alta ou alta de ONGs, 28 municípios possuem densidade média e 32 municípios possuem densidade baixa ou muito baixa de ONGs ambientalistas:

\begin{tabular}{|c|c|c|c|c|}
\hline Município & $\begin{array}{c}\text { População } \\
\text { (IBGE, 2010) }\end{array}$ & $\begin{array}{c}\text { Quantidade } \\
\text { de ONGs }\end{array}$ & Densidade & Classificação \\
\hline Brotas & 21.580 & 4 & 5.395 & \multirow{5}{*}{ Muito alta } \\
\hline Cajobi & 9.768 & 1 & 9.768 & \\
\hline Itobi & 7.546 & 1 & 7.546 & \\
\hline Ubarana & 5.289 & 1 & 5.289 & \\
\hline Ubatuba & 78.801 & 8 & 9.850 & \\
\hline Álvares Machado & 23.513 & 1 & 23.513 & \multirow{6}{*}{ Alta } \\
\hline Amparo & 65.829 & 2 & 32.915 & \\
\hline Assis & 95.144 & 2 & 47.572 & \\
\hline Avaré & 82.934 & 2 & 41.467 & \\
\hline Barra Bonita & 35.246 & 1 & 35.246 & \\
\hline Bernardino de Campos & 10.775 & 1 & 10.775 & \\
\hline
\end{tabular}




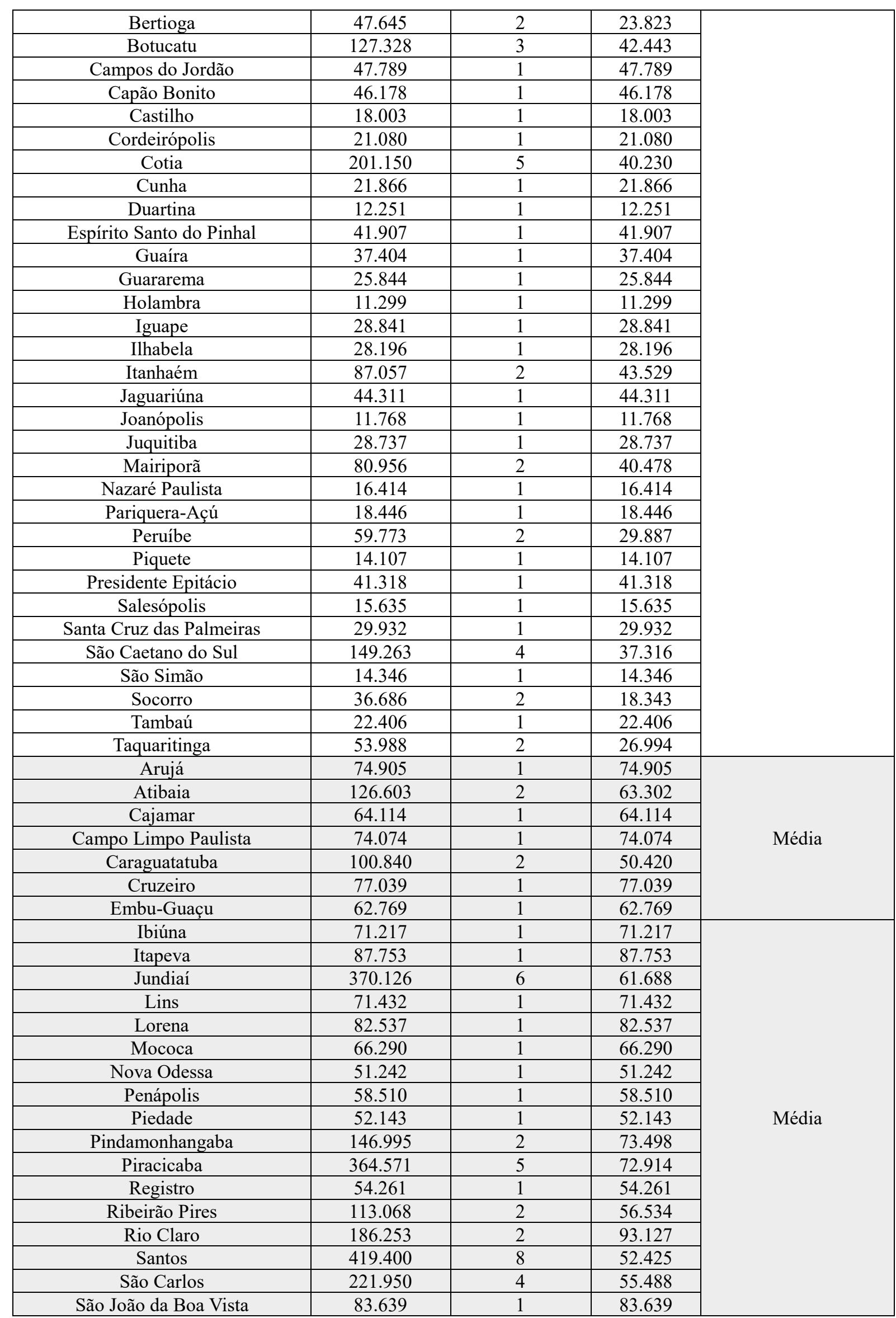




\begin{tabular}{|c|c|c|c|c|}
\hline São José do Rio Pardo & 51.900 & 1 & 51.900 & \multirow{22}{*}{ Baixa } \\
\hline São Sebastião & 73.942 & 1 & 73.942 & \\
\hline Tupã & 63.476 & 1 & 63.476 & \\
\hline Vinhedo & 63.611 & 1 & 63.611 & \\
\hline Araçatuba & 181.579 & 1 & 181.579 & \\
\hline Barueri & 240.749 & 2 & 120.375 & \\
\hline Birigui & 108.728 & 1 & 108.728 & \\
\hline Campinas & 1.080 .113 & 7 & 154.302 & \\
\hline Carapicuíba & 369.584 & 2 & 184.792 & \\
\hline Cubatão & 118.720 & 1 & 118.720 & \\
\hline Diadema & 386.089 & 2 & 193.045 & \\
\hline Franco da Rocha & 131.604 & 1 & 131.604 & \\
\hline Itapevi & 200.769 & 2 & 100.385 & \\
\hline Itu & 154.147 & 1 & 154.147 & \\
\hline Jaú & 131.040 & 1 & 131.040 & \\
\hline Mogi Guaçu & 137.245 & 1 & 137.245 & \\
\hline Praia Grande & 262.051 & 2 & 131.026 & \\
\hline São Bernardo do Campo & 765.463 & 6 & 127.577 & \\
\hline São Paulo & 11.253 .503 & 94 & 119.718 & \\
\hline Sorocaba & 586.625 & 5 & 117.325 & \\
\hline Taubaté & 278.686 & 2 & 139.343 & \\
\hline Valinhos & 106.793 & 1 & 106.793 & \\
\hline Americana & 210.638 & 1 & 210.638 & \\
\hline Bauru & 343.937 & 1 & 343.937 & \\
\hline Embu das Artes & 240.230 & 1 & 240.230 & \\
\hline Guarulhos & 1.221 .979 & 2 & 610.990 & \\
\hline Jacareí & 211.214 & 1 & 211.214 & \\
\hline Marília & 216.745 & 1 & 216.745 & \\
\hline Mauá & 417.064 & 1 & 417.064 & M it bo \\
\hline Mogi das Cruzes & 387.779 & 1 & 387.779 & Muito ba1хa \\
\hline Osasco & 666.740 & 2 & 333.370 & \\
\hline Ribeirão Preto & 604.682 & 3 & 201.561 & \\
\hline Santo André & 676.407 & 2 & 338.204 & \\
\hline São José do Rio Preto & 408.258 & 1 & 408.258 & \\
\hline São José dos Campos & 629.921 & 3 & 209.974 & \\
\hline Sumaré & 241.311 & 1 & 241.311 & \\
\hline
\end{tabular}

Quadro 2 - Municípios atendidos por ONGs ambientalistas e classificação de acordo com a densidade de ONGs (razão da quantidade de ONGs pela população do município)

Fonte: Fossaluza (2015)

Ao analisarmos os dados, pudemos observar que não existe associação direta aparente entre a população do município e a quantidade de ONGs ambientalistas atuantes ali, ou seja, não necessariamente uma cidade mais populosa terá uma densidade maior de ONGs.

A seguir, buscamos confirmar quais das ONGs seguem atuantes. Após as tentativas de contato já expostas, obtivemos respostas de 126 delas; 124 organizações não responderam ao contato, mas possuem telefone e endereço eletrônico ( $e$-mail e/ou site) válidos e atualizados; 26 das organizações listadas não responderam e não possuem endereços eletrônicos e telefones válidos, as quais consideramos como não atuantes. de São Paulo.

Com isso, podemos dizer que encontramos 250 ONGs ambientalistas atuantes no estado

O próximo passo foi identificar, dentre essas, quais desenvolvem ações em EA. Por meio das conversas realizadas por telefone, e-mail e presencialmente ou pela coleta de dados a partir 
de informações disponíveis em meios virtuais, descobrimos que 175 das ONGs ambientalistas realizam ações em $E A$, ou seja, $70 \%$ do total de ONGs atuantes no estado.

A Figura 2 mostra graficamente a distribuição das ONGs no estado, definindo os dados estabelecidos pela pesquisa.

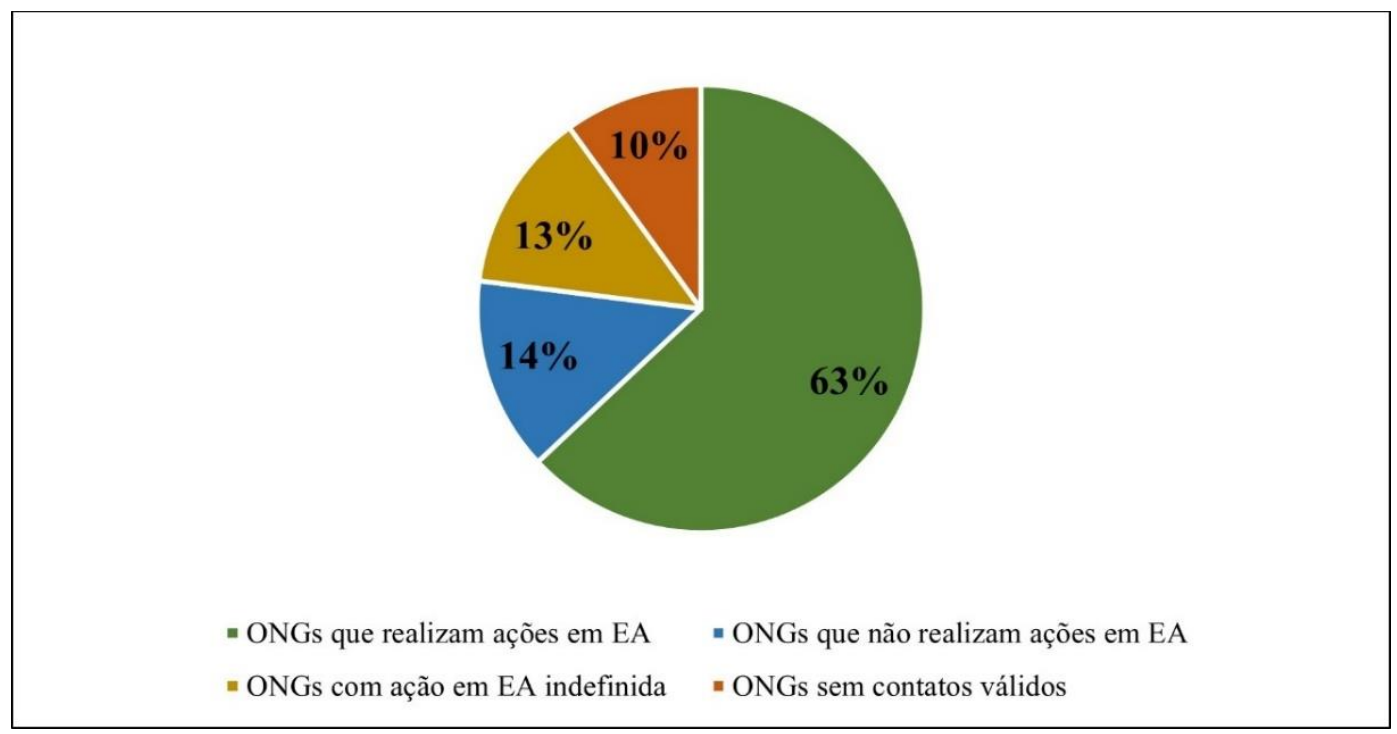

Figura 2 - Síntese da pesquisa quanto à análise da atuação em EA das ONGs ambientalistas Fonte: adaptado de Fossaluza (2015)

A lista das ONGs atuantes em EA no estado de São Paulo ${ }^{10}$ é apresentada no Quadro 3, organizadas de acordo com sua localização.

\begin{tabular}{|c|c|}
\hline Município & Nome da ONG \\
\hline Americana & Ass. Barco Escola da Natureza \\
\hline Amparo & Grupo de Ação e Estudos Ambientais \\
\hline Araçatuba & Poluição Zero \\
\hline Assis & APASS $\mid$ ENVAPA \\
\hline Barra Bonita & MAE Natureza \\
\hline Barueri & Fundação Alphaville $\mid$ Green Building Council Brasil \\
\hline Bauru & Inst. Ambiental Vidágua \\
\hline Bertioga & Ass. PARCEL $\mid$ Renovatec \\
\hline Birigui & AGA \\
\hline Botucatu & Ass. Elo $\mid$ Inst. Floravida $\mid$ SOS Cuesta de Botucatu \\
\hline Brotas & ABROTUR $\mid$ Alaya Ecoturismo \\
\hline Cajamar & Inst. Mata Nativa \\
\hline Campinas & Ass. Novo Encanto de Desenvolvimento Ecológico $\mid$ Ass. Plantando | Paz na Terra \\
\hline IAV $\mid$ Inst. Jequitibá $\mid$ IVG $\mid$ ONG Árvores Centenárias $\mid$ SBE \\
\hline Campo Limpo Paulista & Caminho Verde \\
\hline Campos do Jordão & IAP \\
\hline
\end{tabular}

${ }^{10}$ É necessário considerarmos o recorte temporal do mapeamento realizado, compreendendo que há possibilidade de alteração na lista apresentada ao longo do tempo. É correto afirmar, porém, que não houve grande alteração na quantidade de ONGs listadas nas bases de dados públicas consultadas e que continuam em funcionamento (CNEA e CadEA). Se, em 2014, encontramos 120 ONGs no CNEA e 46 no CadEA (total de 166 organizações), em outubro de 2020 observamos valores similares: 127 ONGs no CNEA e 40 no CadEA (total de 166 organizações). Não podemos dizer o mesmo para as ONGs encontradas nas bases de dados privadas, as quais não possuem atualização recente. 


\begin{tabular}{|c|c|}
\hline Capão Bonito & IDEAS \\
\hline Carapicuíba & Ass. Cultural e Comunitária Zagaia \\
\hline Cordeirópolis & OCAS \\
\hline Cotia & \begin{tabular}{l|l|l} 
AILA & ASERG & Inst. Harmonia na Terra \\
\end{tabular} \\
\hline Cruzeiro & AJADES \\
\hline Cunha & SerrAcima \\
\hline Espírito Santo do Pinhal & Eco Mantiqueira \\
\hline Holambra & SUPREMA \\
\hline Iguape & Inst. LASSUS \\
\hline Itanhaém & AAMAVI \\
\hline Itapeva & Inst. de Pesquisa e Educação Ambiental Planeta Terra \\
\hline Itobi & Ass. Plante Vida \\
\hline Itu & Ass. Mucky de Proteção aos Primatas \\
\hline Jaú & UPJ \\
\hline Joanópolis & Ass. Terceira Via \\
\hline Jundiaí & Mata Ciliar | COATI Jundiaí | ONG Mirim \\
\hline Lins & SOS Rio Dourado \\
\hline Lorena & Inst. Oikos \\
\hline Mairiporã & \begin{tabular}{ll|l} 
Inst. Foco $\mid$ IGC \\
\end{tabular} \\
\hline Marília & Origem \\
\hline Mauá & IBDE do Brasil Meio Ambiente \\
\hline Mococa & Grupo Ecológico Olho D'Água \\
\hline Mogi das Cruzes & OBB \\
\hline Nazaré Paulista & IPE \\
\hline Nova Odessa & Jardim Botânico Plantarum \\
\hline Osasco & AHPCE $\mid$ Sociedade Ecológica de Osasco \\
\hline Pariquera-Açu & AVV \\
\hline Penápolis & Flora Tietê \\
\hline Peruíbe & Estação Eco Guanhanhã $\mid$ MONGUE Proteção ao Ecossistema Costeiro \\
\hline Piedade & IPD - ONG Taipal \\
\hline Pindamonhangaba & Fundação Fórmula Cultural | ISN \\
\hline Piracicaba & Amigos da Lagoa $\mid$ AFG $\mid$ INCA $\mid$ Piracicaba Realizando o Futuro \\
\hline Praia Grande & Ecophalt $\mid$ Projeto Biopesca \\
\hline Presidente Epitácio & APOENA \\
\hline Registro & IDESC \\
\hline Ribeirão Pires & Inst. Acqua \\
\hline Ribeirão Preto & ACEPB \\
\hline Rio Claro & IBEV \\
\hline Santo André & Inst. Triângulo \\
\hline Santos & $\begin{array}{l}\text { ANDES | ASACAR Eduardo Lustoza | IA - Projeto Albatroz | Inst. Caá-Oby | } \\
\text { Inst. EcoFaxina | Inst. Laje Viva }\end{array}$ \\
\hline São Bernardo do Campo & Ass. Aliança-Luz $\mid$ AGDS $\mid$ Ecolmeia $\mid$ Fundação Espaço Eco \\
\hline São Caetano do Sul & Ass. Biomas $\mid \mathrm{IH} \& \mathrm{~N}$ \\
\hline São Carlos & NAPRA $\mid$ ONG Ramudá $\mid$ Proaqua \\
\hline São João da Boa Vista & USPA \\
\hline São José dos Campos & IEPA \\
\hline
\end{tabular}




\begin{tabular}{|c|c|}
\hline São Paulo & $\begin{array}{l}\text { Ag. Ambiental Pick-Upau | Projeto Arrastão | Ass. Águas Claras do Rio Pinheiros } \\
\text { | Ass. Civil Greenpeace | ACHAVE | } \\
\text { AVEPEMA | AEJ | ECOS do Vitória | Ass. Igtiba | Save Brasil | Ass. Reciclázaro | } \\
\text { UNIAGUA | VERDEVER | Catalisa | CEO | Circuito Netas CNDA | CPA Pe. } \\
\text { Bello | Milênio Verde | Espaço | Fundação de Estudos e Pesquisas Aquáticas | } \\
\text { Fundação SOS Mata Atlântica | Grupo Erê || Inst. Akatu | IA-RBMA | Inst. } \\
\text { Baraeté | Inst. Bióleo | IBDN | IDEC | PROAM | Inst. Costa Brasilis | IDELT | Inst. } \\
5 \text { Elementos | IPESA | Inst. de Reciclagem do Adolescente | Inst. ECOAR | Inst. } \\
\text { Ecofuturo | IEB | Inst. GEA | Inst. MAIS | INPA | Inst. Neotropica | Inst. O Direito } \\
\text { por um Planeta Verde | Inst. Putzgrila | IRMV | Inst. Refloresta | ISA | Inst. } \\
\text { Supereco | Inst. Terra \& Mar | Inst. Trata Brasil | Inst. Verdescola | Inst. Via Viva | } \\
\text { KASA | ONG Nossa Tribo | AMA-Brasil | Rede Sol | SOSMAR | SOS Peace | } \\
\text { SOS Praias Brasil | TGI | União dos Escoteiros do Brasil | Vitae Civilis | Vivamar | } \\
\text { ZPB }\end{array}$ \\
\hline Socorro & Ass. Ambientalista Copaíba | GEA \\
\hline Sorocaba & Inst. Viver Sorocaba $\mid$ Pé de Planta $\mid$ Projeto Pérola \\
\hline Sumaré & SHD \\
\hline Taquaritinga & Inst. Planeta Verde \\
\hline Tupã & Ass. de Amigos da Natureza da Alta Paulista \\
\hline Ubarana & ACEPEUB \\
\hline Ubatuba & $\begin{array}{l}\text { Ass. Cunhambebe da Ilha Anchieta | ASSU Ubatuba | Inst. da Árvore | Projeto } \\
\text { TAMAR }\end{array}$ \\
\hline Valinhos & EVA \\
\hline Vinhedo & Elo Ambiental \\
\hline
\end{tabular}

Quadro 3 - ONGs ambientalistas com atuação em EA no estado de São Paulo Fonte: Fossaluza (2015)

Quanto às ONGs ambientalistas atuantes, mas que não encontramos ações em EA, podemos dizer que 39 delas afirmaram não realizar ações em EA, ainda que atuem em ações de caráter ambiental. Não pudemos definir a atuação de 36 das ONGs ambientalistas encontradas no trabalho de mapeamento, já que suas páginas eletrônicas não deixam essa informação clara e/ou não obtivemos respostas nas chamadas telefônicas ou mensagens eletrônicas enviadas, apesar de possuírem contatos ativos.

Além disso, deparamo-nos com uma série de ONGs ambientalistas atuantes em EA, mas que não estão cadastradas em nenhuma das bases de dados: encontramos 27 ONGs nessa situação. Apesar de não termos encontrado publicações que discutam essa questão, acreditamos que sua não inclusão nas bases de dados públicas ou privadas se deva à recente data de fundação dessas ONGs, a problemas de ordem estrutural, à sua inclusão em outras bases de dados não diretamente relacionadas à temática ambiental ou, ainda, à existência de questões jurídicas e de regularização que impeçam seu cadastramento oficial como ONG.

\subsection{Uma análise das ações em educação ambiental realizadas pelas ONGs}

Para obtermos uma amostra significativa do universo de pesquisa, entrevistamos 44 ONGs, de trinta municípios diferentes.

Para a análise, organizamos as respostas em denominações comuns, buscando similaridades entre as diferentes falas para promover uma análise ampla do universo de pesquisa. É importante ressaltar que essa organização em agrupamentos não deve ser compreendida como uma separação em caixas estanques, o que não contemplaria todas as nuances das respostas e da atuação das ONGs ambientalistas. Isto é, apesar de elencarmos agrupamentos que sintetizam as respostas coletadas, temos ciência da possibilidade de diálogo 
entre os agrupamentos e de questões que podem influenciar a comunicação entre o pesquisador e a pessoa entrevistada.

As entrevistas foram analisadas em sua relação com as macrotendências políticopedagógicas descritas por Layrargues e Lima (2014), sendo possível inferir qual a tendência predominante nas ações em EA conduzidas pelas ONGs, a partir dos objetivos dessas ações. No Quadro 4 apresentamos, de forma sintética, os agrupamentos organizados quanto aos objetivos identificados e à quantidade de ONGs nas quais identificamos cada agrupamento.

\begin{tabular}{|c|l|c|}
\hline Macrotendência & \multicolumn{1}{|c|}{ Agrupamento - Objetivos das ações em EA } & Qtd. \\
\hline \multirow{5}{*}{ Conservacionista } & Sensibilização ambiental & 32 \\
\cline { 2 - 3 } & Preservação, conservação, proteção e/ou recuperação do meio ambiente & 26 \\
\cline { 2 - 3 } & Harmonização da relação entre os seres humanos e desses com a natureza & 10 \\
\hline \multirow{5}{*}{ Pragmática } & Mudança de comportamentos individuais & 14 \\
\cline { 2 - 3 } & Transmissão de conteúdos técnico-científicos & 11 \\
\cline { 2 - 3 } & Promoção do consumo consciente & 5 \\
\cline { 2 - 3 } Crítica & Realização de trabalhos de natureza técnica ou jurídica & 7 \\
\hline & Melhoria da qualidade de vida & 6 \\
\cline { 2 - 3 } & Promoção da transformação social & 3 \\
\cline { 2 - 3 } & Formação de líderes comunitários & 2 \\
\cline { 2 - 3 } & Resgate ou valorização de culturas tradicionais & 7 \\
\hline
\end{tabular}

Quadro 4 - Agrupamentos dos objetivos das ações em EA desenvolvidas pelas ONGs

Fonte: Fossaluza (2015)

Novamente, aqui, é importante ressaltar que a aproximação de um determinado agrupamento a uma macrotendência da EA não implica que ele esteja totalmente contido nessa macrotendência. Significa, apenas, que há maior diálogo entre esse agrupamento com as bases teóricas e correntes de EA características de determinada macrotendência.

A primeira macrotendência, a conservacionista, é fortemente ligada aos princípios da Ecologia e da busca pela valorização da dimensão afetiva em relação à natureza, assim como a superação do antropocentrismo, compreendida como necessidade de superar concepções da relação com o ambiente reinantes na cultura humana. De acordo com as análises de Layrargues e Lima (2014), essa tendência não é a mais hegemônica nas ações em EA atualmente, apesar de ter um longo histórico de atuação.

A seguir, apresentamos os agrupamentos de objetivos identificados nas entrevistas, compartilhando alguns trechos das respostas de modo a garantir o anonimato da pessoa entrevistada:

\section{1) Sensibilização ambiental}

Definida como um dos "primeiros momentos do processo educativo que insere o educando num mundo que se quer ver (re)descoberto, ou simplesmente notado" (HIGUCHI; AZEVEDO, 2004, p. 68). Apesar disso, é, muitas vezes, equivocadamente considerada como um processo educativo completo em si mesmo.

Além disso, o termo é usado para descrever ações que visam ao estímulo da dimensão afetiva ou sentimental dos/as participantes em relação à natureza. A sensibilização ambiental foi o objetivo mais citado para as ações em EA desenvolvidas por ONGs. 
Nas falas das pessoas entrevistadas, fica visível a presença da busca pela dimensão afetiva da EA: "aqui, nessa visita, se procura resgatar essa relação com a natureza (E4, 2015, p. 83). "Sensibilizar a população em geral sobre os problemas ambientais causados pelo descarte irregular do lixo eletrônico (E2, 2015, p. 83).

É interessante notar que essa dimensão afetiva da sensibilização ambiental é comumente confundida e chamada de conscientização. Contudo, consideramos que elas possuem significados distintos. Paulo Freire (1979, p. 15) discute que "a conscientização implica, pois, que ultrapassemos a esfera espontânea de apreensão da realidade, para chegarmos a uma esfera crítica na qual a realidade se dá como objeto cognoscível e na qual o homem assume uma posição epistemológica".

Entretanto, há entrevistados/as que reconhecem a distinção entre essas ações, as quais são realizadas devido às condições específicas de ordem temporal ou financeira: "o objetivo geral é a sensibilização. Como eu tenho pouco tempo com esses grupos, eu não consigo fazer muita coisa $(\mathrm{E} 4,2015$, p. 84).

Essa é uma diferença notada entre ONGs alinhadas à macrotendência conservacionista e à crítica: uma das ONGs consideradas como mais alinhada à última macrotendência citou a sensibilização ambiental, mas enfatizou que ela é parte de um processo mais amplo:

\begin{abstract}
O objetivo da EA é sensibilizar as pessoas para o tema e principalmente na tentativa de mudança de comportamento. Eles terem conhecimento dos processos produtivos, dos ciclos, ciclo de vida, de produção, do processo de produções, consumo... Elas terem consciência, depois de um longo processo de sensibilização, informação de muito tempo... Então, o objetivo principal da nossa EA é que elas tenham o conhecimento e mudança de comportamento, atuar diferente, transformar situações precárias, de melhoria de qualidade de vida... Elas almejam principalmente a melhoria da qualidade de vida, esse é um dos objetivos principais das ações que a ONG faz (E22, 2015, p. 84).
\end{abstract}

\title{
2) Preservação, conservação, proteção elou recuperação do meio ambiente
}

No agrupamento em tela, as falas são intimamente relacionadas à macrotendência conservacionista, comum em organizações que têm como foco determinada espécie ou bioma.

Esse foi um objetivo citado pela maioria das ONGs, o que está claro nos excertos: "Então, a EA é para isso: trabalhar com as crianças, jovens e adultos para resgatar o meio ambiente (E12, 2015, p. 85). "O objetivo [do curso da ONG] é justamente a preservação. Porque, para nós, o que importa: nós não vamos ter tempo. O que está acontecendo hoje com a atmosfera, que é falta de água e oxigênio, não adianta plantarmos árvores pequenas [...] (E7, 2015, p. 85). "Despertar através de ações variadas a necessidade da preservação ambiental (E2, 2015, p. 85).

É importante destacarmos que algumas ONGs desempenham papel fundamental para a manutenção ou recuperação de uma determinada espécie ou área natural. É o caso de ONGs atuantes em áreas de unidades de conservação ou que possuem uma espécie-bandeira, as quais têm desempenhado papel de crescente relevância, a partir de 2016, dada o intenso desmonte na política ambiental brasileira.

3) Harmonização da relação entre os seres humanos e desses com a natureza

Nesse agrupamento, as ONGs enfatizam a necessidade de harmonizar as relações interpessoais e entre ser humano e natureza, como na sensibilização ambiental. Há, porém, maior similaridade à corrente da EA holística, nomeada por Sauvé (2005).

Vejamos um excerto: 
Tudo tem que ser, de alguma maneira, dentro desse espírito do entendimento do que cabe nas relações humanas e na relação com o planeta. Essa que é a nossa visão de mundo [...]. A questão da EA, no fundo, não podia ser uma coisa específica no nosso trabalho. A gente não acha que 'Vamos agora fazer EA agora'. Tudo é EA. Porque tudo que trata das condições de vida do ser humano na sua relação com o planeta tem que ser com esse ponto de vista (E5, 2015, p. 86).

Na segunda macrotendência da EA, a pragmática, encontramos posições também conservadoras, que podem ser vistas como reflexo do surgimento e expansão do Neoliberalismo. A ênfase dessa macrotendência não é somente a alteração das relações afetivas, mas, sim, a mudança de comportamentos para a diminuição de impactos no ambiente. É comum o uso de termos como "economia e consumo verde, responsabilidade socioambiental, certificações, mecanismos de desenvolvimento limpo e ecoeficiência produtiva" (LAYRARGUES; LIMA; 2014, p. 31). Ainda, a tecnologia é vista como a solução dos problemas de ordem ambiental. Segundo esses autores, essa macrotendência tem predominado nas ações em EA.

Entendemos que os objetivos sintetizados nos agrupamentos abaixo se relacionam a essas concepções:

\section{4) Mudança de comportamentos individuais}

Esse agrupamento se refere a alterações individuais ou coletivas no relacionamento com resíduos, água, alimentos etc. A concepção é de que a mudança comportamental individual permitiria a criação de uma sociedade mais sustentável, presente no lema agir localmente, pensar globalmente, ou que a soma de pequenas ações individuais teria como consequência uma transformação da sociedade.

É importante identificar a influência da Pedagogia Tecnicista nesse agrupamento. Saviani (2008) aborda o objetivo dado à educação por essa teoria da aprendizagem: o importante é o comportamento adequado do educando para ser inserido no sistema de produção vigente, não enfatizando o processo educativo em si.

Nas entrevistas com as ONGs, encontramos citações mais genéricas ou relacionadas à geração de resíduos, como: "objetiva a mudança de comportamento e melhoria na qualidade do ambiente" (E15, 2015, p. 89). "o próprio consumidor-gerador de resíduo precisa entender a responsabilidade dele (E4, 2015, p. 89).

Além das ONGs, a mudança de comportamentos individuais como foco das ações em EA tem sido bastante explorada por empresas.

\section{5) Transmissão de conteúdo técnico-científico}

Sintetiza a ideia da necessidade de oferecer a maior quantidade de informações aos/às educandos/as para que possam fazer o manejo técnico adequado dos recursos naturais.

No contexto desse agrupamento, os problemas ambientais são causados, principalmente, pela falta de conhecimento. Conforme o excerto inserido, evidencia-se a crença no desenvolvimento tecnológico como meio de superação da problemática ambiental: "É preciso conhecer, para depois amar e depois preservar (E3, 2015, p. 89).

\section{6) Promoção do consumo consciente}

Refere-se às ações que visam mudanças na forma como nos relacionamos com o consumo. Há raras referências ao modo de produção em si. 
Neste objetivo visualizamos, claramente, a expressão do Capitalismo Verde e a realização de ações individuais e coletivas para promover reformas positivas no meio ambiente: "A atividade foi criada há mais ou menos 4 anos atrás com o objetivo de valorizar a água tratada e incentivar o consumo da água filtrada para mudar essa cultura de consumo em larga escala de água em garrafa $(E 33,2015$, p. 90). "O projeto nasceu como um projeto para a gente trabalhar as questões de consumo consciente e educação para estilos mais sustentáveis de vida ou para a sustentabilidade (E37, 2015, p. 90).

Encontramos relatos de ONGs que fomentam o consumo de certos produtos em detrimento a outros, assim como valorizam produtos considerados mais sustentáveis. Essa ação, apesar de propor uma melhoria na qualidade de vida do indivíduo, não discute o modo de produção em si. Tem-se a ideia de que o consumidor detém o poder de alterar o quadro de degradação ambiental ao forçar as empresas produtoras a mudarem sua conduta em prol de uma produção mais verde.

7) Realização de trabalhos de natureza técnica ou jurídica

Optamos por dispor este objetivo, aqui, por avaliá-lo como uma proposta de atuação reformista na sociedade, apesar de sua importância.

Nas falas coletadas, ficou clara a importante ação ativista das ONGs, tendo em vista a melhoria das condições ambientais ou punição de poluidores.

[...] essa advogada, quando viu essa situação, ela começou a pegar firme. Ela fez parceria com o Ministério Público e a gente começou a fazer EA - porque eu não acho que deixa de ser educação, mas não é uma educação formal. Há a educação pelo amor, que é você ensinar na escola [...]. Tem também a educação pela dor [...]. Digo que é educação pela dor é você através da Promotoria denunciar no jornal, pôr a boca no trombone sobre o que está sendo feito errado. É um tipo de educação (E44, 2015, p. 91).

$\mathrm{Na}$ terceira macrotendência, a crítica, incluímos agrupamentos que enfatizam o enfrentamento político das desigualdades e da injustiça socioambiental, tendo como meta a transformação social.

Nessa macrotendência estão incluídas as "Educação Ambiental Popular, Emancipatória, Transformadora e no Processo de Gestão Ambiental" e nela são apresentados conceitos como "Cidadania, Democracia, Participação, Emancipação, Conflito, Justiça Ambiental e Transformação Social” (LAYRARGUES; LIMA, 2014, p. 33).

\section{8) Melhoria da qualidade de vida}

Apesar de esse termo poder ser relacionado a ambas as correntes anteriormente citadas, agrupamos, aqui, falas que extrapolam mudanças a nível individual.

Ainda que de forma tímida, notamos o objetivo de enfrentar as desigualdades sociais e trabalhar para a construção de modelos societários mais justos, com a promoção de ações em comunidades em situação de risco, como transparece no fragmento: "a ONG tem como seu objetivo principal a promoção do bem-estar socioambiental das pessoas e do planeta, assegurando assim a dignidade e uma vida socialmente justa e ambientalmente equilibrada que todo cidadão tem por direito" (E14, 2015, p. 92).

\section{9) Resgate ou valorização de culturas tradicionais}


Movimentos que propõem alternativas de transformação social ao trazer à luz conhecimentos, hábitos, formas de organização social e de relação do ser humano com a natureza que têm sido suprimidos ou desqualificados pelas classes dominantes.

Vejamos as falas pertinentes ao tema:

\begin{abstract}
Acreditava-se, na época [da realização do projeto], que a agroecologia atenderia essa demanda porque, além de preservar ambientalmente o lugar, ele envolvia mão de obra familiar e a questão da economia solidária para comercialização, acesso a políticas públicas via PNAE, geração de renda às famílias e, principalmente, a conservação do meio ambiente através da agroecologia (E10, 2015, p. 92-93).

Nossa missão é contribuir com a construção de sociedades sustentáveis [...]. E sustentabilidade pressupõe muito mais que a preservação ambiental, ela pressupõe também uma sociedade mais justa, mais equitativa, o profundo respeito à cultura local, à diversidade $[\ldots](\mathrm{E} 31,2015$, p. 93) .
\end{abstract}

\title{
10) Formação de líderes comunitários
}

Nesse agrupamento, há constantes menções à atuação de educandos/as como agentes transformadores/as em seus territórios.

A organização comunitária é de extrema importância para as classes e grupos historicamente explorados e marginalizados no enfrentamento das desigualdades socioambientais: "Esses projetos (de EA) estão focando comunidades. [...] A ideia é formar lideranças comunitárias (E13, 2015, p. 93).

\section{1) Promoção da transformação social}

As falas são claras ao se posicionarem contrárias ao modelo atual de organização da sociedade e atuantes para sua transformação. Ainda que esse não seja a finalidade imediata das ações realizadas, ele é o horizonte que guia a atuação da organização.

\footnotetext{
Quando a comunidade olha, se organiza, e trabalha, propõe soluções para o problema, você prepara tanto a comunidade quanto o poder público para se sentar, dialogar e resolver o problema, aí muda. Fica um ambiente um pouco mais seguro para os dois lados [...], de possibilidade de realização (E13, 2015, p. 94).

Nós temos o entendimento de que não é possível você mudar, que as pessoas mudem sua atitude em relação ao ambiente se não tiverem a compreensão do porquê isso é necessário. Porque você fazer conservação ambiental, recuperação de áreas, de bacias, diminuir as emissões de carbono, tudo que a gente for fazer em prol de uma melhoria ambiental requer a mudanças onerosas financeiramente, requer uma mudança de atitude, e isso a gente só consegue fazer com a compreensão do contexto, do porquê. E isso só se dá por meio da educação, de uma educação libertária, EA que não seja neutra, que seja realmente inclusiva... Então, nós temos essa compreensão (E31, 2015, p. 94).
}

De forma sintética, podemos afirmar que $85 \%$ dos objetivos das ações em EA realizadas por ONGs ambientalistas possuem viés conservador (macrotendências conservacionista e pragmática), enquanto $15 \%$ das citações são mais alinhadas às concepções críticas da EA.

Notamos que várias ONGs entrevistadas citaram objetivos alinhados a diferentes macrotendências político-pedagógicas durante suas entrevistas. Se, por um lado, essa constatação pode ser vista como uma falta de clareza teórica da ONG, por outro lado evidencia as contradições inerentes à realização de ações educativas na sociedade capitalista. 
Assim, para avançar nessa análise, buscamos determinar qual a concepção teórica predominante em cada uma das ONGs, mesmo que essas apresentassem seus objetivos alinhados a diferentes vertentes (Figura 3).

Cientes da simplificação que essa escolha possa trazer, reforçamos que ela não busca diminuir a importância, a coerência e o comprometimento do trabalho desenvolvido pelas organizações.

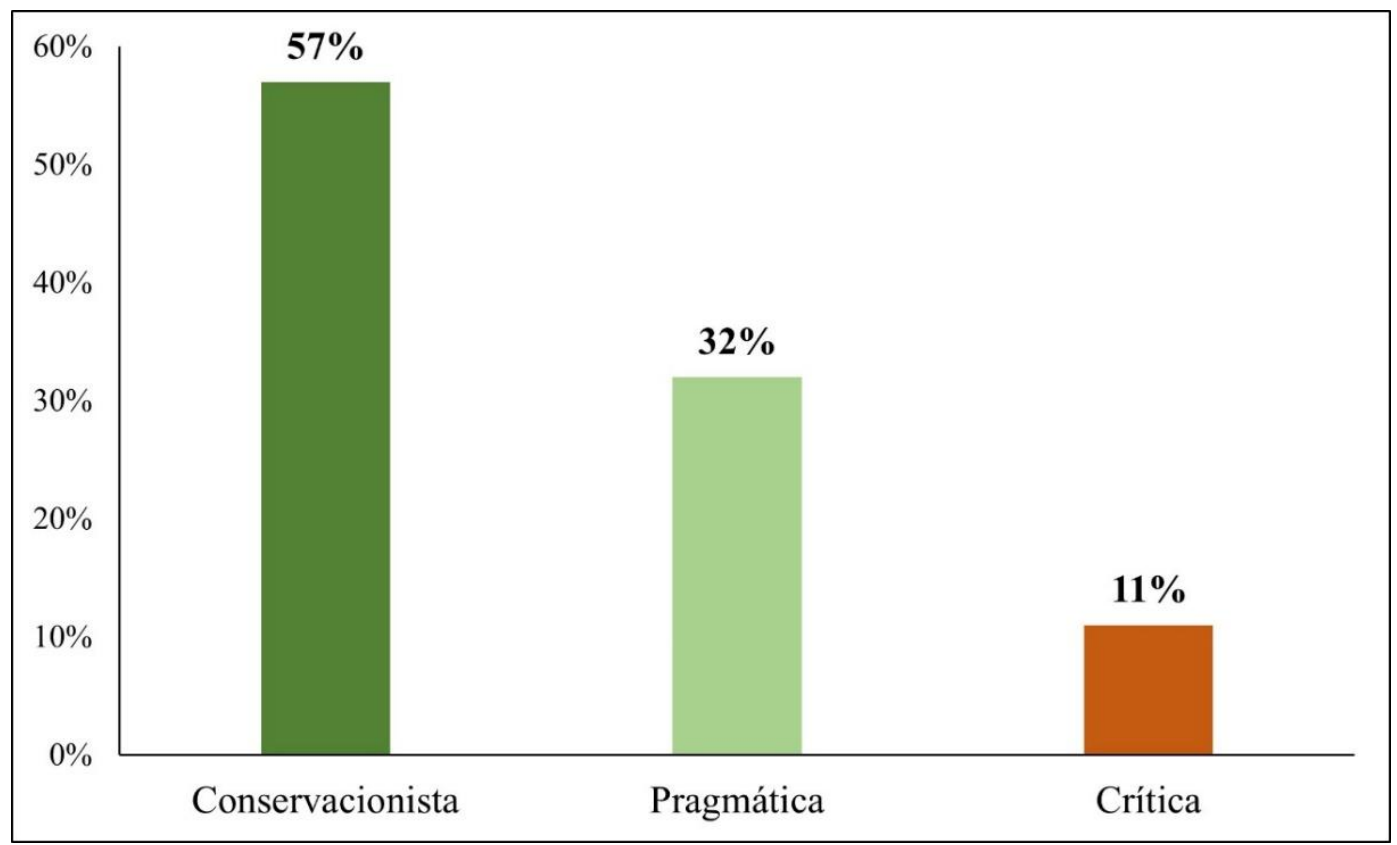

Figura 3 - Macrotendências político-pedagógicas predominantes nas ONGs ambientalistas Fonte: adaptado de Fossaluza (2015)

Esse resultado nos permite avaliar, de forma mais apropriada, a importância da hipótese inicial para compreendermos as macrotendências que fundamentam as ações em EA das ONGs.

A Figura 2 nos mostra que em 89\% das ONGs entrevistadas predominam objetivos alinhados a macrotendências conservadoras da EA (conservacionista e pragmática). Por outro lado, $11 \%$ das ONGs têm em seus objetivos um maior diálogo com a macrotendência crítica da EA.

Assim, por considerarmos que ações em EA mais alinhadas a concepções conservadoras se distanciam do que consideramos como os propósitos plenos do processo educativo crítico, vemos que, em geral, as ações em EA realizadas por ONGs ambientalistas no estado de São Paulo tendem a ter pouco impacto no que diz respeito à apropriação crítica dos determinantes ambientais em nossas sociedades, quando consideramos os objetivos previstos para tais ações.

Isso significa dizer que, apesar da sua extensa distribuição territorial e ampla atuação, as ONGs ambientalistas paulistas tendem a trazer contribuições pouco relevantes para a implantação e ao desenvolvimento de propostas educacionais críticas, transformadoras e emancipatórias, as quais contribuíram para o fortalecimento de ações em prol do desenvolvimento de sociedades ecologicamente equilibradas e socialmente justas.

\section{Conclusão}

O processo de mapeamento das ONGs ambientalistas apresentou uma série de dificuldades no acesso a informações. Desde o momento de escolha das bases de dados a serem 
utilizadas até o contato com as organizações, pudemos notar a necessidade de fontes de informações mais fidedignas e atualizadas.

Apesar da sua ampla atuação na sociedade, as informações sobre as ONGs ambientalistas estão dispersas em vários bancos de dados que não compartilham todas as informações entre si e que não possuem atualização constante. É importante destacar que, em relação à atualização das informações cadastradas, os bancos de dados públicos apresentam maior constância e validade ao longo do tempo.

No mapeamento, encontramos 276 ONGs ambientalistas no estado de SP, sendo que $63 \%$ (175 ONGs) delas atuam com EA, valor menor do que imaginávamos.

É importante ressaltar que, certamente, existem mais ONGs ambientalistas atuantes em EA no estado, como pudemos notar ao encontrarmos 27 ONGs atuantes que não se encontravam cadastradas nas bases de dados consultadas (FOSSALUZA, 2015).

Ao analisarmos a qualidade das ações em EA realizadas pelas ONGs, lembramos que algumas generalizações apresentadas podem induzir a erros, já que desconsideram contextos históricos, econômicos, geográficos, culturais, sociais, políticos e ambientais específicos de cada localidade. Nesse sentido, reforçamos que o trabalho não visa separar as ONGs em compartimentos estanques ou, ainda, diminuir a importância dos trabalhos que desenvolvem. A proposta é fomentar a reflexão sobre a forma como atuam, tendo como base referenciais teóricos críticos.

De forma sintética, quanto a seus objetivos e a orientação político-pedagógica, apesar de confirmarmos a hipótese de que sua atuação pode ser vista como conservadora, notamos que a maioria das ONGs tende a ser mais alinhada à macrotendência político-pedagógica conservacionista, ao contrário do que Layrargues e Lima (2014) apontaram: os autores apresentam uma tendência a mais ações alinhadas à macrotendência pragmática.

Essa constatação nos mostra que, apesar do avanço de ações pragmáticas em EA, $a$ vertente conservacionista predomina nas ONGs ambientalistas. Atualmente, acreditamos que, frente à crescente expansão da fronteira agrícola brasileira, a crimes ambientais de grande porte e à escalada de ataques do governo à conservação de áreas naturais, essas ações têm readquirido grande relevância.

Também, pudemos notar contradições entre as concepções teóricas apresentadas pelas ONGs e suas próprias ações em EA. Notamos contradições entre o conteúdo das entrevistas e as práticas educativas realizadas pelas instituições.

Por fim, podemos dizer, com base nos resultados apresentados, que as ações em EA realizadas por ONGs ambientalistas abrangem boa parte do território e da população paulistas. Por outro lado, nosso trabalho indica que sua qualidade tende a ser limitada se tomarmos como base referenciais teóricos críticos em EA, evidenciando o predomínio de ações político e pedagogicamente conservadoras.

É relevante afirmar que as informações obtidas a partir das entrevistas semiestruturadas podem não apresentar toda a realidade das pessoas que atuam no dia a dia das organizações, como educadoras: nossos dados foram obtidos, prioritariamente, a partir de pessoas em cargos de coordenação ou direção, opção que pode esconder a práxis educativa de quem está atuando diretamente com a população atendida, conflitos dentro da própria instituição e a influência das fontes de financiamento nas ações realizadas pelas organizações.

Finalmente, este processo investigatório nos mostrou o quão amplo e complexo é o universo de atuação das ONGs ambientalistas: como encontramos na literatura da área, correse um sério risco ao agrupar todas essas organizações na mesma definição, dadas suas diferentes formas de atuação, manutenção, financiamento e objetivos. 


\section{Agradecimentos}

Agradecemos à CAPES (Mestrado DS, 03/2013-03/2014) e à FAPESP (MS-2, processo 2014/08084-1, 08/2014-02/2015) pela concessão das bolsas que viabilizaram este estudo, a todas as ONGs ambientalistas participantes da pesquisa e à Universidade Estadual Paulista (UNESP).

\section{Referências}

ALBUQUERQUE, A. C. C. Terceiro setor: história e gestão de organizações. São Paulo: Summus Editorial, 2006.

ALMEIDA JÚNIOR, A. R.; GOMES, H. L. R. M. Gestão ambiental e interesses corporativos: imagem ambiental ou novas relações com o ambiente? Ambiente \& Sociedade, São Paulo, v. 15, n. 1, p. 157-177, Abr. 2012.

ANÁLISE EDITORIAL. Análise Gestão Ambiental. São Paulo: Análise Editorial, 2013. (Anuário).

BARDIN, L. Análise de Conteúdo. Tradução de Luís Antero Reto e Augusto Pinheiro. São Paulo: Edições 70, 2011.

BONI, V.; QUARESMA, S. J. Aprendendo a entrevistar: como fazer entrevistas em ciências sociais. Em Tese: Revista Eletrônica Dos Pós-graduandos em Sociologia Política da UFSC, Florianópolis, v. 2, n. 1, p.68-80, 2005.

BRASIL. Educação ambiental: por um Brasil sustentável. ProNEA, marcos legais \& normativos. 5 ed. Brasília: MMA, 2018.

BRASIL. Ministério do Meio Ambiente. Cadastro Nacional de Entidades Ambientalistas 2013. Brasília: MMA, 2013.

CARLETON-HUG, A.; HUG, J. W. Challenges and opportunities for evaluating environmental education programs. Evaluation and Program Planning [online], London/New York, v. 33, n. 2, p.159-164, mai. 2010.

CARVALHO, I. C. M. Educação ambiental: a formação do sujeito ecológico. 4 ed. São Paulo: Cortez, 2008.

DIEGUES, A. C. O mito moderno da natureza intocada. 6 ed. São Paulo: Hubitec/Nupauv-USP/CEC, 2008.

EAMES, C.; COWIE, B.; BOLSTAD, R. An evaluation of characteristics of environmental education practice in New Zealand schools. Environmental Education Research, [s.1], v. 14, n. 1, p. 35-51, Fev. 2008.

FERNANDES, R. C. Privado, porém Público: o Terceiro Setor na América Latina. Rio de Janeiro: Relume Dumará, 1994. 
FOSSALUZA, A. S. As ações em educação ambiental realizadas por Organizações Não Governamentais no estado de São Paulo: alcances e limitações. 2015. 205 f. Dissertação (Mestrado em Educação para a Ciência) - Universidade Estadual Paulista, Bauru, 2015.

FREIRE, P. Conscientização: teoria e prática da libertação: uma introdução ao pensamento de Paulo Freire. Tradução de Kátia de Mello e Silva. São Paulo: Cortez \& Moraes, 1979.

FREIRE, P. Pedagogia da autonomia: saberes necessários à prática educativa. 63 ed. Rio de Janeiro/São Paulo: Paz e Terra, 2020.

GUANABARA, R.; GAMA, T.; EIGENHEER, E. M. Contribuições para a construção de uma matriz para avaliação de projetos de educação ambiental. Educ. Pesq., São Paulo, v. 35, n. 2, p. 399-411, Mai./Ago. 2009.

HAGUETTE, T. M. F. Metodologias qualitativas na Sociologia. 12 ed. Petrópolis: Vozes, 2010.

HIGUCHI, M. I. G.; AZEVEDO, G. C. Educação como processo na construção da cidadania ambiental. Revista Brasileira de Educação Ambiental, Brasília, v. 0, [s.n], p. 63-70, Nov. 2004.

IBGE - Instituto Brasileiro de Geografia e Estatística. Censo Demográfico 2010. Brasília: IBGE, 2010.

LAYRARGUES, P. P.; LIMA, G. F. C. As macrotendências político-pedagógicas da educação ambiental brasileira. Ambiente \& Sociedade, Campinas, v. 17, n. 1, p.23-40, Jan./Mar. 2014.

MADE IN FOREST. ONG Educação e Cultura Ambiental.

MINAYO, M. C. S.; DESLANDES, S. F.; CRUZ NETO, O.; GOMES, R. (Orgs.). Pesquisa Social: teoria, método e criatividade. 12 ed. Petrópolis: Vozes, 1994.

ONU - Organização das Nações Unidas. Handbook on Non-Profit Institutions in the System of National Accounts. Nova Iorque: United Nations Publication, 2003.

PINTO, C. R. J. ONG e a Política no Brasil: Presença de Novos Atores. Dados Rev. De Cienc. Soc. [online], Rio de Janeiro, v. 49, n. 3, p. 651-670, 2006.

RODRIGUES, J. N.; LOUREIRO, C. F. B. A crise socioambiental e a atuação de ONG ambientalistas no campo educacional. Linhas Críticas, Brasília, v.18, n. 36, p. 379-394, Mai./Ago., 2012.

SAITO, C. H. As mútuas interfaces entre projetos e ações de educação ambiental e de gestão de recursos hídricos: subsídios para políticas de estado. Ambiente \& Sociedade, Campinas, v. 14, n. 1, p. 213-227, Jan./Jul. 2011.

SÃO PAULO. Estado. Cadastro de Entidades Ambientalistas do Estado de São Paulo. São Paulo: Coordenadoria de Educação Ambiental, 2013.

SAUVÉ, L. Currents in Environmental Education: Mapping a Complex and Evolving Pedagogical Field. Canadian Journal of Environmental Education, Thunder Bay, Canadá, v. 10, n. 1, p. 11-37, 2005.

SAVIANI, D. Escola e democracia. Campinas: Autores Associados, 2008. 
SILVA, M. R. Educação Ambiental e atuação das ONGs: uma análise das ações da ecoa em mato grosso do sul. 2012. 169 f. Dissertação (Mestrado em Geografia) - Universidade Federal da Grande Dourados, Dourados, 2012.

TEIXEIRA, L. A.; TALAMONI, J. L. B.; TOZONI-REIS, M. F. C. A relação teoria e prática em projetos de educação ambiental desenvolvidos em um bairro em Bauru, SP, Brasil. Ciênc. Educ. [online], Bauru, v. 19, n. 3, p. 657-676, 2013.

TOZONI-REIS, M. F. C. (Org.). A pesquisa-ação-participativa em educação ambiental: reflexões teóricas. São Paulo: Anna Blume/Fapesp; Botucatu: Fundibio, 2007.

TOZONI-REIS, M. F. C. Educação Ambiental: natureza, razão e história. 2 ed. Campinas: Autores Associados, 2008.

TOZONI-REIS, M. F. C. Educação e sustentabilidade: relações possíveis. Olhar de Professor, Ponta Grossa, v. 14, n. 2, p. 293-308, Dez. 2011. 